Asian J. Med. Biol. Res. 2020, 6 (2), 237-243; doi: 10.3329/ajmbr.v6i2.48055

\author{
Asian Journal of \\ Medical and Biological Research \\ ISSN 2411-4472 (Print) 2412-5571 (Online) \\ www.ebupress.com/journal/ajmbr
}

\title{
Article \\ Nurses' knowledge and practices regarding prevention and management of pressure ulcer for hospitalized patient
}

\author{
Hasan Mahfuz Reza ${ }^{1}$, Chinmoy Kanti Das $^{2}$, China Rani Mittra ${ }^{3}$ and Ashees Kumar Saha ${ }^{4}$ \\ ${ }^{1}$ Urban Primary Health Care Services Delivery Project-II, Kushtia Municipality, Kushtia, Bangladesh \\ ${ }^{2}$ Department of Community Medicine, Rajshahi Medical College, Rajshahi, Bangladesh \\ ${ }^{3}$ Upazilla Health Complex, Abhaynagar, Jashore, Bangladesh \\ ${ }^{4}$ Upazilla Health Complex, Bagha, Rajshahi, Bangladesh
}

*Corresponding author: Ashees Kumar Saha, Senior Staff Nurse, Upazilla Health Complex, Bagha, Rajshahi, Bangladesh. Phone: +8801729989859; E-mail: ashees2020@gmail.com

Received: 12 May 2020/Accepted: 18 June 2020/ Published: 30 June 2020

\begin{abstract}
Pressure ulcers have been labelled as one of the most expensive and physically debilitating complications in the 20th century. After cancer and heart diseases pressure ulcers are the third most expensive disorder. Several studies have indicated that nurses' knowledge and practices about pressure ulcer prevention and management are inadequate. This is a descriptive co-relational study aimed to assess nurses' knowledge and practices related to pressure ulcer prevention and management. It also examines the relationships between nurses' knowledge and practice with respect to pressure ulcer prevention and management. The subjects were nurses working at Rajshahi Medical College Hospital. Three hundred nurses were selected for this study, two hundred and ninety four nurses were completed the questionnaire and response rate was $98 \%$. Three tools were used for data collection: Demographic, Knowledge and Practice questionnaire. Data were analysed by descriptive and Pearson product-moment correlation statistics. The findings showed that nurses had a moderate level of knowledge and a moderate level of practice when we categorized the findings according to their age, working experience and educational level they scored low level of knowledge. There was a significant correlation was found between nurses knowledge and practice regarding pressure ulcer prevention and management $(r=.136, p>.05)$. Findings of the present study suggest that nurses need to increase knowledge on pressure ulcer prevention and management in order to improve nursing practice in this.
\end{abstract}

Keywords: pressure ulcer; knowledge and practices; prevention and management

\section{Introduction}

A pressure ulcer is localized injury to the skin and/or underlying tissue usually over a bony prominence, as a result of pressure, or pressure in combination with shear and/or friction. It is also called decubitus ulcers, bedsores, or pressure sores, range in severity from reddening of the skin to severe, deep craters with exposed muscle or bone. Pressure ulcers significantly threaten the well-being of patients with limited mobility. Although 70 percent of ulcers occur in persons older than 65 years (Whittington et al., 2000), younger patients with neurologic impairment or severe illness are also susceptible. Prevalence rates range from 4.7 to 32.1 percent in hospital settings (Kaltenthaler et al., 2001) and from 8.5 to 22 percent in nursing homes (Coleman et al., 2002). There were no sufficient records about pressure ulcer in the hospitals of Bangladesh. However, Hoque et al. (1999) conducted a study among paralyzed patients in Bangladesh and found that 94 out of 247 patients (38\%) developed pressure ulcers. Until recently, there was no known guideline for the prevention of pressure ulcers in Bangladesh. The study of Hoque et al. (1999) was considered as an important land mark in the pressure ulcer prevention issue. A study conduct in Jordanian, describe that the nurses have insufficient knowledge about pressure ulcer prevention as compared with national pressure ulcer advisory panel guidelines. Therefore it is 
important for all nurses to be aware of standards guidelines to prevent any complication associated with pressure ulcers to promote patient safety and better outcomes. Patient suffer with pain and discomfort because of pressure ulcer and also cause prolong illness, delay rehabilitation, increase patient's hospital stay, and may lead to disability and even death . Epidemiologic studies conducted in multiple countries demonstrate a clinically relevant prevalence in multiple settings (Coleman et al., 2002). The reported prevalence in the United States varies from $10 \%$ to $17 \%$ in the acute care setting, from $0 \%$ to $29 \%$ in home care, and from $2.3 \%$ to $28 \%$ in the long-term care setting. Reported incidence rates vary from $0.4 \%$ to $8 \%$ in acute care, $0 \%$ to $17 \%$ in home care, and $2.2 \%$ to $23.9 \%$ in long-term care facilities (Ayello and Braden, 2002). While the overall prevalence of PU tends to be high, most are lower-stage ulcers. For example, Ayello reported a PU prevalence rate of 8.6\%, but slightly more than half $(55 \%)$ were stage I PUs. Whittington and colleagues evaluated PU prevalence in a multisite hospital study that included 17,560 patients (Ayello et al., 2004). Factors that enhance nurses' knowledge and practice regarding pressure ulcer prevention and management were effective education, willingness to change clinical practice, availability of resources, sufficient equipment supplies, administrative support, and increased multidisciplinary team collaboration (Clarke et al., 2005). One study found that lack of updating in nurses' education decreased the level of knowledge among nurses with many years' experience (Pancorbo-Hidalgo et al., 2007). It was stated that nurses who were not being trained in pressure ulcer prevention possessed lower level of knowledge and practice as compared to those being trained in pressure ulcer prevention program (Pancorbo-Hidalgo et al., 2007) Other social and organizational factors that affect nurses to incorporate knowledge into practice included: 1) inadequate leadership, 2) lack of education and training program, 3) lack of evidence-base practice guideline, 4) patients over load, 5) shortage of staff, 6) insufficient time and cooperation from other professionals, and 7) lack of equipment and facilities, and inadequate pain management (Moore and Price, 2004). Pressure ulcer prevention guideline is one of the core components of the national healthcare strategic planning services. Guidelines are the instructions for nurses to provide up-to-date scientific clinical evidence on specific areas to ensure consistent and appropriate clinical practice (Langemo et al., 2008). A guideline is a systematically developed statement for practitioners that help to take decision about appropriate nursing practice for defined areas (Langemo et al. 2008). Previous studies showed that in order to deliver high quality of care, it was essential for nurses to provide evidence-based nursing practice. In this regards, nurses must have knowledge of risk factors and preventive strategies of pressure ulcer development (Panagiotopoulou and Kerr, 2002). Currently, there is no evidence on Bangladeshi nurses' knowledge and practice regarding pressure ulcer prevention and management. Therefore, it was important to explore and observe the nurses' knowledge and practice regarding pressure ulcer prevention and management for hospitalized patients at Rajshahi Medical College Hospital in Bangladesh.

\section{Materials and Methods}

\subsection{Study area and period}

The hospital based study was conducted at Rajshahi Medical College Hospital (RMCH), Rajshahi, Bangladesh. The study was carried out from October 2017 to April 2018. Total number of nurses working in this hospital was 1200 . The study was conducted in different wards mainly surgery unit, medicine unit, orthopaedic unit, neuro-surgery unit, neuro-medicine unit, paediatric, post-operative coronary care unit and others.

\subsection{Collection of data}

The questionnaires were distributed among the total number of 300 nurses working in Rajshahi Medical College Hospital. 294 out of 300 questionnaires (98\% response rate) were completed and returned by the nurses. Random sampling technique was used.

\section{The inclusion criteria-}

1. Working as a full time senior staff nurses in (RMCH).

2. Having roles and responsibilities connected with direct patient care.

3. Having educational status of at least three years diploma in nursing.

4. At least 2 years of working experience as a senior staff nurse.

\section{The exclusion criteria-}

1. Nurses who are not willing to participate in the study.

2. Nurses who have not 2 years of working experience as a senior staff nurse. 


\subsection{Statistical analysis}

Data were checked, entered and analyzed using the computer program Statistical Package for Social Sciences (SPSS) version 22. The statistical analyses include frequencies and mean \pm SD. For all analyses, $p$ value $<0.05$ was considered statistically significant.

\section{Results and Discussion}

\subsection{Demographic characteristics of the nurses'}

A descriptive cross-sectional study was carried out among 294 nurses working in Rajshahi Medical College Hospital, Rajshahi. The demographic characteristics of the nurses are shown in Table 1.

Table 1. Frequency and percentage of nurses' demographic characteristics $(\mathrm{N}=294)$.

\begin{tabular}{lll}
\hline Variables : & Frequency (n) & Percentage (\%) \\
\cline { 1 - 2 } Age range (years) & & \\
$21-30$ & 160 & 54.4 \\
$31-40$ & 85 & 28.9 \\
$41-50$ & 41 & 13.9 \\
$>50$ & 8 & 2.8 \\
Total & 294 & 100.0 \\
Sex & & \\
Male & 52 & 17.7 \\
Female & 242 & 82.3 \\
Total & 294 & 100.0 \\
& & \\
Level of Education & & \\
Diploma in nursing & 175 & 59.5 \\
Bachelor in nursing & 102 & 34.7 \\
MSc in nursing & 9 & 3.1 \\
MPH & 8 & 2.7 \\
Total & 294 & 100.0 \\
& & \\
Experience in nursing profession (in years) & & 84.0 \\
$2-10$ & 247 & 10.2 \\
$11-20$ & 30 & 5.1 \\
$21-30$ & 15 & 0.7 \\
$>30$ & 2 & 100.0 \\
Total & 294 & \\
Formal training on pressure ulcer & & 0.0 \\
Yes & & 100.0 \\
No & 0 & 100.0 \\
Total & 294 & \\
\hline
\end{tabular}

Table 1 has shown the demographic characteristics of the nurses. Among 294 nurses 52 (17.7\%) were males and $242(82.3 \%)$ females, respectively. Majority of them $160(54.4 \%)$ were from age 21-30 years, 85 (28.9\%) age from 31-40 years, 41 (13.9 \%) age from 41-50 years and $8(2.8 \%)$ were age 50 years above. Regarding educational status majority of them were Diploma in nursing 175 (59.5\%), BSc in Nursing $102(34.7 \%)$, MSc in Nursing $9(3.1 \%)$ and MPH 8 (2.7\%) degree holders, respectively. Nurses have $2-10$ years $247(84.0 \%)$, have $11-20$ years $30(10.2 \%)$, have $21-30$ years $15(5.1 \%)$ and have > 30 years $2(0.7 \%)$ experience in nursing profession. However, all of them had not received any formal training on pressure ulcer prevention and management.

\subsection{Nurses' knowledge regarding pressure ulcer prevention and management}

Nurses' knowledge regarding pressure ulcer prevention and management in Rajshahi Medical College hospital are shown in Table 2. 
Table 2. Frequency and percentage of nurses in each category of knowledge level regarding pressure ulcer prevention and management $(\mathrm{N}=294)$.

\begin{tabular}{lll}
\hline Knowledge level : & N & \% \\
\hline Very low $(<60 \%)$ & 79 & 26.9 \\
Low $(60-69.99 \%)$ & 47 & 16.0 \\
Moderate $(70-79.99 \%)$ & 138 & 46.9 \\
High $(80-89.99 \%)$ & 29 & 9.9 \\
Very high $(90-100 \%)$ & 1 & 0.3 \\
Total & $\mathbf{2 9 4}$ & $\mathbf{1 0 0 . 0}$ \\
\hline
\end{tabular}

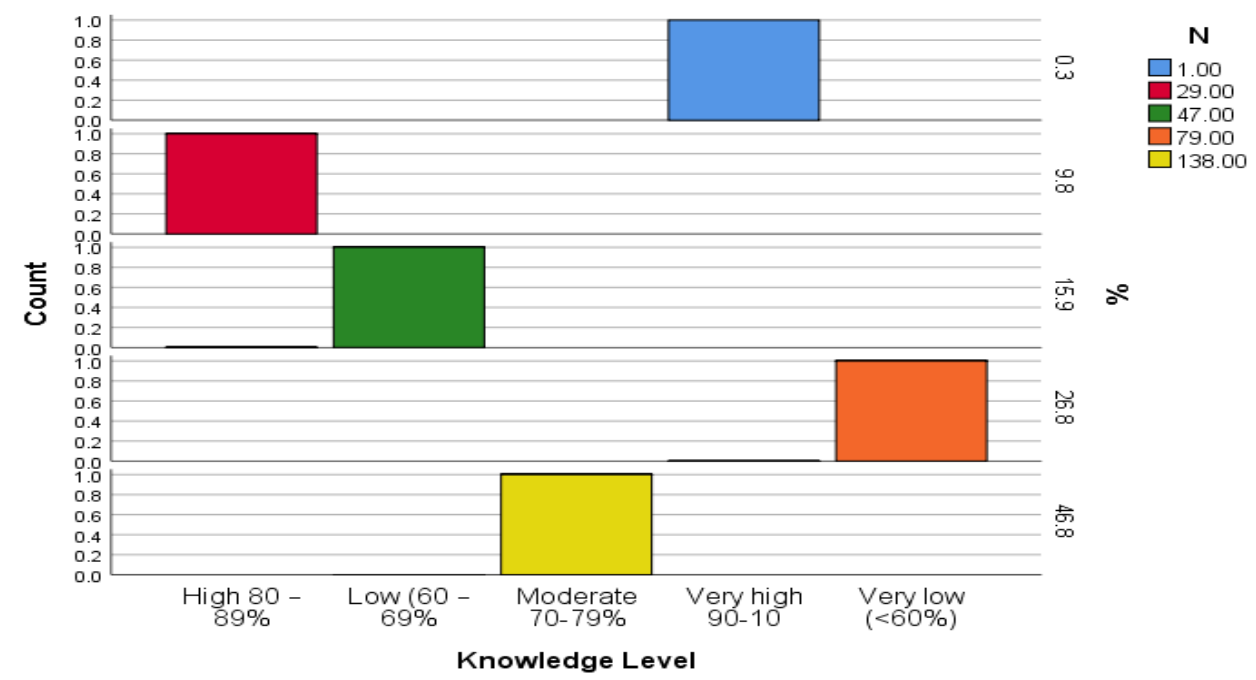

Figure 1. Frequency and percentage of nurses in each category of knowledge level regarding pressure ulcer prevention and management $(\mathrm{N}=294)$.

Table 2 and Figure 1 have shown the number and frequency of nurses who were in each category of knowledge level. It was found that $42.9 \%$ of nurses possessed very low (26.9\%) to low (16.0\%) level of knowledge. $(46.9 \%)$ had a moderate level of knowledge. Very few nurses had a high $(9.9 \%)$ and very high $(0.3 \%)$ level of knowledge regarding pressure ulcer prevention and management.

\subsection{Nurses' practices regarding pressure ulcer prevention and management}

Nurses' practices regarding pressure ulcer prevention and management in Rajshahi Medical College hospital are shown in Table 3.

Table 3. Frequency and percentage of nurses in each category of practice level regarding pressure ulcer prevention and management $(\mathrm{N}=\mathbf{2 9 4})$.

\begin{tabular}{lll}
\hline Practices level : & N & \% \\
\hline Very low $(<60 \%)$ & 6 & 2.1 \\
Low $(60-69.99 \%)$ & 13 & 4.4 \\
Moderate $(70-79.99 \%)$ & 195 & 66.3 \\
High $(80-89.99 \%)$ & 80 & 27.2 \\
Very high $(90-100 \%)$ & 0 & 0.0 \\
Total & 294 & 100.0 \\
\hline
\end{tabular}




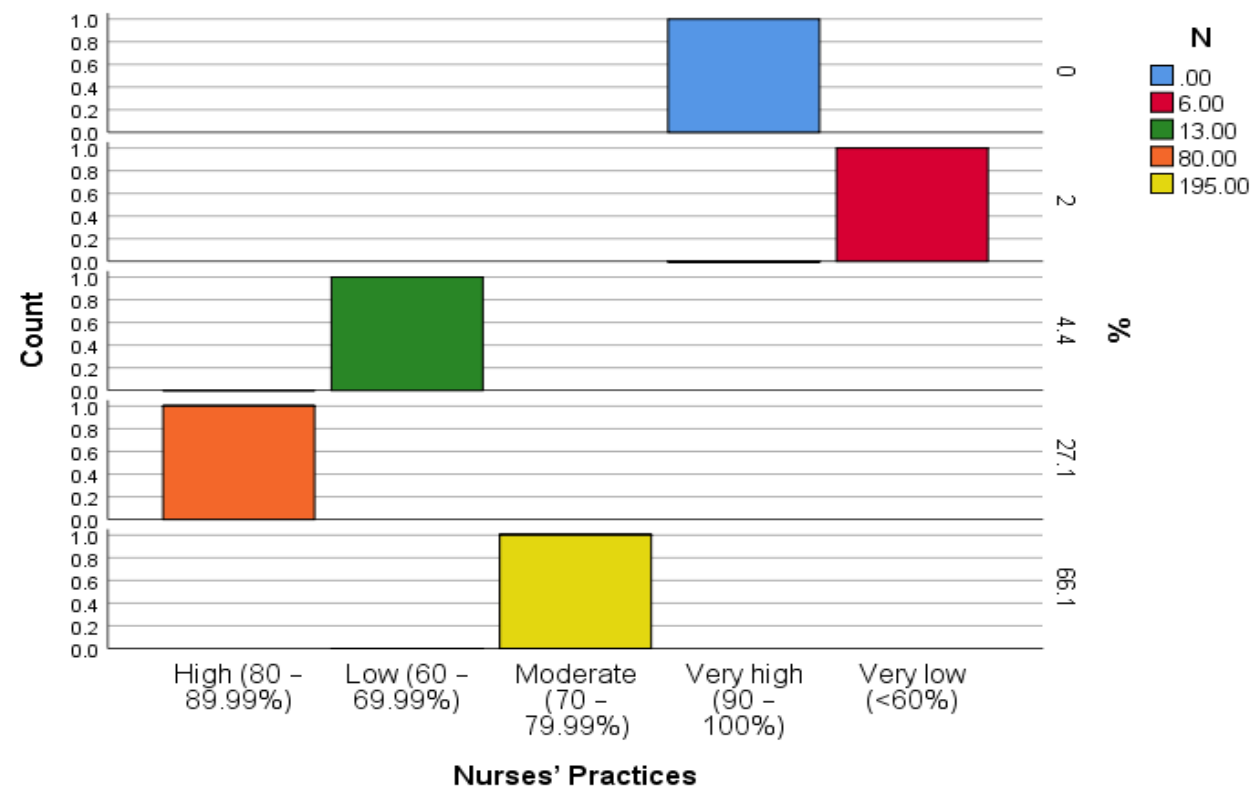

Figure 2. Frequency and percentage of nurses in each category of practice level regarding pressure ulcer prevention and management $(\mathrm{N}=\mathbf{2 9 4})$.

Table 3 and Figure 2 have shown the number and frequency of nurses who were in each category of practice level. It was found that $2.1 \%$ of nurses scored very low, $4.4 \%$ nurses scored low level of practice. $66.3 \%$ nurses scored moderate level of practice. $27.2 \%$ nurses scored high level and none had very high $(0.0 \%)$ level of practice regarding pressure ulcer prevention and management.

3.4. Nurses' knowledge and practice level regarding pressure ulcer prevention and management according to age, educational qualification and working experience

Frequency, Knowledge and Practice Level of Nurses according to age, educational qualification and working experience regarding Pressure Ulcer Prevention and management are shown in Table 4.

Table 4. Frequency, Knowledge and Practice Level of Nurses according to age, educational qualification and working experience regarding Pressure Ulcer Prevention and management ( $N=294)$.

\begin{tabular}{llll}
\hline Variables: & N & Knowledge level & Practice level \\
\hline Age range (years) & & & \\
$21-30$ & 160 & Low & High \\
$31-40$ & 85 & Low & High \\
$41-50$ & 41 & Low & High \\
$>50$ & 8 & Low & High \\
& & & \\
Educational qualification & 175 & Low & Moderate \\
Diploma in nursing & 102 & Low & Moderate \\
Bachelor in nursing & 17 & Low & Moderate \\
MSc in nursing+MPH & & & \\
& & & \\
Working experience & 247 & Low & Moderate \\
$2-10$ years & 30 & Low & Moderate \\
$11-20$ years & 15 & Low & Moderate \\
$21-30$ years & 2 & Moderate & Moderate \\
$>30$ years & & & \\
\hline
\end{tabular}

Table 4 has shown that Nurses of variable ages and educational qualifications scored low level of knowledge and high level of practice. Again nurses of variable working experiences scored low level of knowledge and high level of practice, except working experience of 2 nurses more than 30 years scored moderate level of knowledge and moderate level of practice. 
3.5. Relationship between nurses' knowledge and practice regarding pressure ulcer prevention and management

Correlation analysis revealed that there was a significant relationship between nurses' knowledge and practice are shown in Table 5.

Table 5. Pearson Product-Moment Correlation Coefficients between nurses' knowledge and practice regarding pressure ulcer prevention and management $(N=294)$.

\begin{tabular}{|c|c|c|c|}
\hline & & Knowledge & Practice \\
\hline \multirow{5}{*}{ Knowledge } & Pearson Correlation & 1 & $.136^{*}$ \\
\hline & Sig. (2-tailed) & & .020 \\
\hline & Sum of Squares and Cross-products & 1896.000 & 363.571 \\
\hline & Covariance & 6.471 & 1.241 \\
\hline & $\mathrm{N}$ & 294 & 294 \\
\hline \multirow{5}{*}{ Practice } & Pearson Correlation & $.136^{*}$ & 1 \\
\hline & Sig. (2-tailed) & .020 & \\
\hline & Sum of Squares and Cross-products & 363.571 & 3770.898 \\
\hline & Covariance & 1.241 & 12.870 \\
\hline & $\mathrm{N}$ & 294 & 294 \\
\hline
\end{tabular}

\section{Conclusions and Recommendations}

The prevention and management of pressure ulcers is of great importance. Based on the findings of the study, it could be concluded that nurses had a moderate level of knowledge and a moderate level of practice regarding pressure ulcer prevention and management. When we categorized the findings according to their age, educational level and working experience of nurse's knowledge and practice they scored low level of knowledge and moderate level of practice, except working experience of nurses more than 30 years scored moderate level of knowledge and moderate level of practice. The study reported that heavy workload, shortage of resources and lack of training as the dominant barriers face nurses to prevention and management of pressure ulcer. So, nurses' education should be enhanced regarding prevention and management of pressure ulcer.

Following recommendations are put forward to improve nurses' knowledge and practice regarding the prevention and management of pressure ulcers: Update the available policy on wound management and incorporate new guidelines for Pressure ulcer prevention and management. Increase the training opportunities for all nurses and provide an equal opportunity for everyone to attend. Provide evidence based resources required for the prevention and management of Pressure ulcer. Develop a statistical data base for maintaining and recording all cases of Pressure ulcer that will assist for future planning regarding its prevention and management.

\section{Conflict of interest}

None to declare.

\section{References}

Ayello EA and B Braden, 2002. How and why to do pressure ulcer risk assessment. Adv. Skin Wound Care, 15: 125-131.

Ayello EA, S Baranoski, C Lyder and J Cuddigan, 2004. Pressure ulcers. In S. Baranoski, \& E. A. Ayello (Eds.), Wound care essentials: Practice principles (pp. 240-270). Philadelphia: Lippincott William \& Wilkins.

Clarke HF, C Bradley, S Whytock, S Handfield, R VanderWal and S Groound, 2005. Pressure ulcers: Implementation of evidence based nursing practice. J. Adv. Nurs., 49: 578-590.

Coleman EA, JM Martau, MK Lin and AM Kramer, 2002. Pressure ulcer prevalence in long-term nursing home residents since the implementation of OBRA '87. Omnibus Budget Reconciliation Act. J. Am. Geriatr. Soc., 50: 728-732.

Hoque MF, C Grangeon and K Reed, 1999. Spinal cord lesions in Bangladesh: An epidemiological study 19941995. Spinal Cord, 37: 858-861.

Kaltenthaler E, MD Whitfield, SJ Walters, RL Akehurst and S Paisley, 2001. UK, USA and Canada: how do their pressure ulcer prevalence and incidence data compare? J. Wound Care, 10: 530-535.

Langemo D, J Cuddigan, M Baharestani, CR Ratliff, ME Posthauer, J Black and S Garber, 2008. Pressure ulcer guidelines: "Minding the gaps" when developing new guidelines. Adv. Skin Wound Care, 21: 213-217. 
Moore Z and P Price, 2004. Nurses attitude, behavior, and perceived barrier towards pressure ulcer prevention. J. Clin. Nurs., 13: 942-951.

Pancorbo-Hidalgo PL, FP Garcia-Fernandez, IM Lopez-Medina and J Lopez-Ortega, 2007. Pressure ulcer care in Spain: Nurses' knowledge and clinical practice. J. Adv. Nurs., 58: 327-338.

Panagiotopoulou K and SM Kerr, 2002. Pressure area care: An exploration of Greek nurses' knowledge and practice. J. Adv. Nurs., 40: 285-296.

Whittington K, M Patrick and JL Roberts, 2000. A national study of pressure ulcer prevalence and incidence in acute care hospitals. J. Wound Ostomy Continence Nurs., 27: 209-215. 